\title{
Poder de Inchamento e Microscopia Eletrônica de Varredura de Diferentes Genótipos de Arroz de Terras Altas
}

\author{
Raíza C. Fonseca \& Priscila Z. Bassinello
}

O arroz apresenta uma ampla faixa de conteúdo de amilose, pode ser utilizado em diversas aplicações industriais, principalmente, para uso alimentício. O objetivo deste estudo foi caracterizar genótipos de arroz com diferentes teores de amilose, quanto a tamanho dos grânulos e poder de inchamento. Foram analisados onze genótipos de plantio de terras altas provenientes da safra 2013 da Embrapa Arroz e Feijão. Foram observados três distintos grupos de amilose (ceroso, baixo e intermediário). O tamanho dos grânulos de arroz caracterizou-se poliédrico, irregular e amidos ricos em amilose mostraram poder de inchamento inferior, mesmo submetidos a maiores temperaturas.

Palavras-chaves: amilose; qualidade de grãos; Oryza sativa.

The rice, to present a wide range amylose content can be used in various industrial applications, especially for food use. The aim of this study was to characterize rice genotypes with different levels of amylose as the size of the beads and swelling power. They were analyzed eleven upland planting genotypes from the 2013 harvest of Embrapa Rice and Beans. We observed three different groups of amylose (waxy, low and intermediate). The size of rice grains characterized polyhedral, jagged and high amylose starches show less swelling power even subjected to higher temperatures.

Keywords: amylose; grain quality; Oryza sativa. 


\section{Introdução}

$\mathrm{O}$ arroz é um dos cereais mais consumidos em todo o mundo e está inserido na dieta de grande parte da população mundial, atuando como importante fonte de carboidratos, principalmente, no Brasil. A qualidade de grãos em arroz influencia o valor do produto no mercado, na aceitação do produto pelo consumidor e na adoção de novas cultivares ${ }^{1}$. $\mathrm{O}$ amido de arroz, por apresentar uma ampla faixa no seu conteúdo de amilose, pode ser utilizado em diversas aplicações industriais, principalmente, para uso alimentício, como ingrediente em vários alimentos, tais como, sobremesas, produtos de panificação, fórmulas infantis, produtos hipoalergênicos, como espessante, estabilizador de coloides, agente gelificante e de volume, adesivo, na retenção de água, dentre outros ${ }^{2}$.

A análise da qualidade de grãos baseia-se no resultado de não somente um, mas de uma série de testes específicos, diretos ou indiretos, que em conjunto, servem como indicadores da qualidade de uma determinada cultivar ou linhagem que está sendo desenvolvida. A escolha do tipo de análise a ser adotada irá depender fundamentalmente da infraestrutura disponível e dos objetivos do programa de melhoramento genético ${ }^{3}$.

A utilização da microscopia eletrônica de varredura (MEV) para observação de tamanho e concentração dos grânulos de amido para diferentes teores de amilose, além de propriedades funcionais de poder de inchamento do amido, ambos auxiliam a desvendar o perfil de comportamento do amido de arroz ${ }^{4,5}$. Segundo SINGH et al. $(2003)^{2}$, quando as moléculas de amido são aquecidas em excesso de água, a estrutura cristalina é rompida, e as moléculas de água formam pontes de hidrogênio entre a amilose e amilopectina, expondo seus grupos hidroxil, o que causa um aumento no inchamento e na solubilidade do grânulo.

O poder de inchamento (PI) indica a habilidade do amido em hidratar em condições específicas de cozimento. Essa propriedade funcional do amido é extremamente importante na sua forma de aplicação, pois a escolha do amido para determinado tipo de utilização está baseada em suas propriedades ${ }^{6}$.

Esse poder de inchamento e solubilidade varia de acordo com a fonte do amido, fornecendo evidências da interação entre as cadeias de amido dentro dos domínios amorfos e cristalinos. A extensão destas interações é influenciada pela proporção amilose: amilopectina e pelas características dessas moléculas.

Sendo assim, o presente trabalho teve como objetivo caracterizar os parâmetros de tamanho de grânulo de amido e determinar o poder de inchamento de onze diferentes genótipos de terras altas.

\section{Material e Método}

Foram analisadas farinhas (150 mesh) de onze genótipos de arroz com faixas distintas de amilose, pertencentes ao plantio terras altas, multiplicados na fazenda Capivara da Embrapa Arroz e Feijão em Santo Antônio de Goiás/GO, safra 2013, quanto ao Teor de Amilose (TA) por cromatografia de exclusão de tamanho - SEC7. Os amidos foram extraídos por método alcalino com $\mathrm{NaOH}$ 0,1\% (WANG; WANG, 2004) ( $^{8}$ e analisados quanto ao grau de hidratação pelo poder de inchamento (PI) segundo Schoch $(1964)^{9}$, sendo determinado nas temperaturas de $55^{\circ} \mathrm{C}, 65^{\circ} \mathrm{C}, 75^{\circ} \mathrm{C}, 85^{\circ} \mathrm{C}$ e $95^{\circ} \mathrm{C}$. Ambas as análises de TA e PI foram realizadas no Laboratório de Grãos e Subprodutos da Embrapa Arroz e Feijão. Os resultados foram submetidos à análise de variância (ANOVA) e as médias comparadas pelo teste de Tukey ao nível de $5 \%$ de significância.

Os amidos dos onze genótipos foram avaliados em DSM 940A microscópio eletrônico de varredura, Jeol, JSM-6610, equipado com EDS, (Thermo Scientific, Spectral Imaging, Tokyo, Japão), com aumentos de 5000 vezes, realizado no Laboratório Multiusuário de Microscopia de Alta Resolução na Universidade Federal de Goiás.

\section{Resultados e Discussão}

Os teores de amilose dos onze genótipos foram agrupados em três faixas distintas, conforme apresentado na Tabela 1. Observa-se, a partir dos resultados apresentados, que os genótipos variaram entre ceroso (dois genótipos), baixo (cinco genótipos) e intermediário teor de amilose (quatro genótipos), confirmando, assim ,que se trata de linhagens contrastantes. Este conteúdo de amilose é considerado um dos principais parâmetros para a qualidade tecnológica e de consumo do arroz ${ }^{10}$.

$\mathrm{O}$ amido de arroz pode apresentar diferentes quantidades de amilose variando entre 1 a $37 \%$ e classifica-se em quatro grupos: baixo teor de amilose (12-20\%), conteúdo 
Tabela 1. Agrupamentos dos genótipos quanto ao teor de amilose ${ }^{1}$.

\begin{tabular}{|c|c|c|}
\hline Classe de TA & Genótipo & TAA(\%) \\
\hline \multirow{3}{*}{ Ceroso } & N2583 & $0,14 \mathrm{~d} \pm 0,05$ \\
\cline { 2 - 3 } & BGA6030 & $0,15 \mathrm{~d} \pm 0,06$ \\
\hline \multirow{4}{*}{ Baixo } & Xingu & $9,79 \mathrm{c} \pm 0,89$ \\
\cline { 2 - 3 } & SBT432 & $9,84 \mathrm{c} \pm 0,67$ \\
\cline { 2 - 3 } & Douradão & $10,80 \mathrm{c} \pm 0,58$ \\
\cline { 2 - 3 } & SBT282 & $11,02 \mathrm{c} \pm 1,57$ \\
\cline { 2 - 3 } & Primavera & $18,94 \mathrm{~b} \pm 1,58$ \\
\hline \multirow{4}{*}{ Intermediário } & Acrefino & $20,48 \mathrm{ab} \pm 0,68$ \\
\cline { 2 - 3 } & Cambará & $20,62 \mathrm{ab} \pm 0,48$ \\
\cline { 2 - 3 } & Arroz da Terra & $21,04 \mathrm{ab} \pm 1,57$ \\
\cline { 2 - 3 } & BGA4243 & $22,29 \mathrm{a} \pm 1,28$ \\
\hline
\end{tabular}

${ }^{t}$ Valores correspondem à média ( $\left.n=3\right)$; letras diferentes minúsculas na coluna, diferem significativamente pelo teste de Tukey $(P<0,05)$.

intermediário de amilose (20-25\%), alto teor de amilose $(>25 \%)$ e ceroso (pouco a nenhum teor de amilose) $)^{11}$. Cultivares com baixo teor de amilose apresentam grãos aquosos e pegajosos no cozimento; com alto teor, apresentam grãos secos, soltos e mais duros e com teor intermediário, possuem grãos soltos e macios ${ }^{12}$. Amidos com elevados níveis de amilose são associados com a menor resposta glicêmica e o esvaziamento mais lento do trato gastrointestinal que aqueles com baixos níveis de amilose ${ }^{13}$.

Em relação à estrutura granular dos amidos de arroz de diferentes genótipos, observou-se variação no tamanho e na forma, conforme determinado por microscopia eletrônica de varredura. Segundo Juliano $(1985)^{14}$, Franco et al. (2001) $)^{15}$, Qi-hua et al. (2009) $)^{16}$, o tamanho dos grânulos do amido de arroz é muito pequeno variando de 3 a $9 \mu \mathrm{m}$ em formas poligonais irregulares. $\mathrm{O}$ tamanho granular encontrado neste estudo foi de 4,33-6,21 $\mu \mathrm{m}$ em diferentes amidos de arroz (Tabela 2). Algumas fotomicrografias dos grânulos de amido de arroz para diferentes classes de teor de amilose foram apresentadas nas Figuras de 1 a 3. Os grânulos de amido foram observados como sendo poliédricos, de formas irregulares e com faces distintas e angulares. Outros autores observaram perfis similares nos grânulos de amido de $\operatorname{arroz}^{17,18,19,20}$.O genótipo, a técnica de isolamento, práticas agronômicas, condições climáticas e a biossíntese do amido foram relatados como sendo responsáveis pela diversidade do grânulo de amido ${ }^{17,19}$.
Tabela 2. Médias dos tamanhos granulares de diferentes amidos de arroz medidos por meio da análise de microscopia eletrônica de varredura (MEV).

\begin{tabular}{|c|c|}
\hline \multirow{2}{*}{ Genótipo } & MEV \\
\cline { 2 - 2 } & Grânulo de amido $(\mu \mathrm{m})$ \\
\hline N2583 & $4,98 \mathrm{ab} \pm 0,54$ \\
\hline BGA6030 & $5,25 \mathrm{ab} \pm 0,47$ \\
\hline Xingu & $5,93 \mathrm{a} \pm 0,73$ \\
\hline SBT432 & $5,24 \mathrm{ab} \pm 1,14$ \\
\hline Douradão & $4,84 \mathrm{ab} \pm 0,66$ \\
\hline SBT282 & $5,16 \mathrm{ab} \pm 072$ \\
\hline Primavera & $4,33 \mathrm{~b} \pm 0,90$ \\
\hline AcreFino & $5,16 \mathrm{~b} \pm 1,09$ \\
\hline Cambará & $5,11 \mathrm{ab} \pm 0,62$ \\
\hline Arroz da Terra & $6,21 \mathrm{a} \pm 0,88$ \\
\hline BGA4243 & $5,03 \mathrm{ab} \pm 0,82$ \\
\hline
\end{tabular}

Valores correspondem à média $(n=3) \pm$ desvio-padrão; letras diferentes na mesma coluna diferem significativamente pelo teste de Tukey $(P<0,05)$. MEV $=$ microscopia eletrônica de varredura.

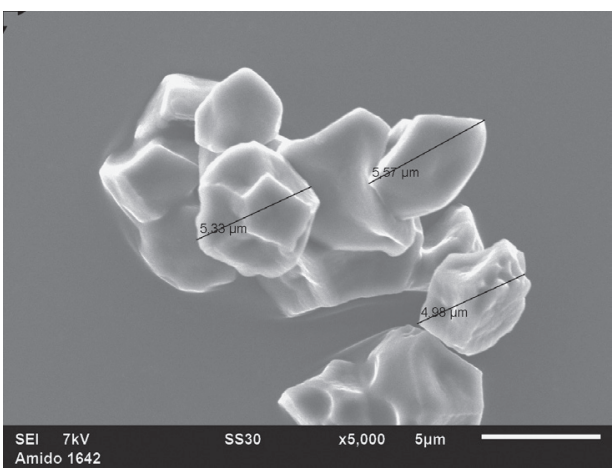

Figura 1. Fotomicrografia obtida por microscopia eletrônica de varredura dos grânulos de Amido 1642 (genótipo: N2583-ceroso).

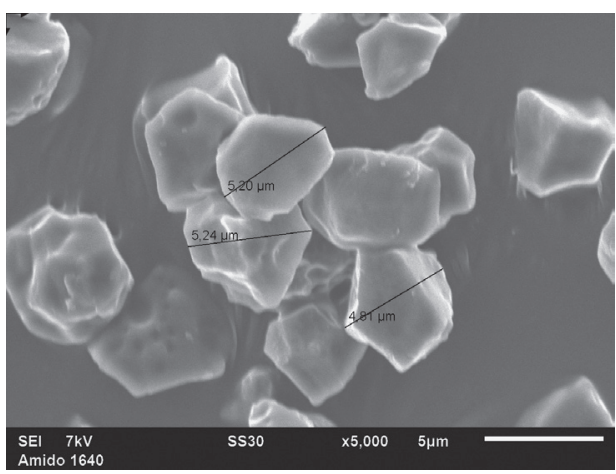

Figura 2. Fotomicrografia obtida por microscopia eletrônica de varredura dos grânulos de Amido 1640 (genótipo: Primavera-baixo TA). 


\section{Artigo Geral 32}

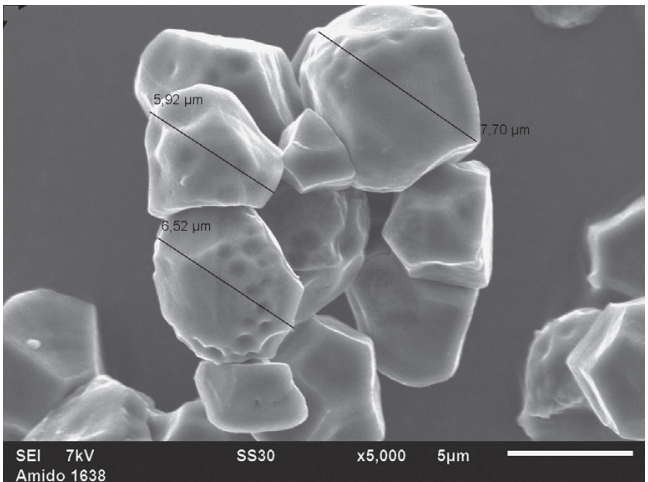

Figura 3. Fotomicrografia obtida por microscopia eletrônica de varredura dos grânulos de Amido 1638 (genótipo: Arroz da Terra-TA intermediária).

O tamanho e o formato dos grânulos podem influenciar as propriedades físico-químicas do amido. Alguns autores mencionam a relação entre o tamanho de grânulo de amido e a digestibilidade ${ }^{21}$, o teor de amilose, poder de intumescimento, a solubilidade, a capacidade de absorção de água e a textura ${ }^{22,23}$.

O PI dos onze genótipos avaliados nas diferentes temperaturas de aquecimento variou, consideravelmente, mostrando um aumento linear com a temperatura (Figuras 4 a 6). A forte influência da temperatura sobre a capacidade de retenção de água relaciona-se com a maior vibração das moléculas do grânulo de amido sob altas temperaturas ${ }^{17,24,25}$. Os amidos pertencentes à classe de teor de amilose ceroso (N2583 e BGA6030) apresentaram nas temperaturas de 30 ${ }^{\circ} \mathrm{C}, 55^{\circ} \mathrm{C}$ e $65^{\circ} \mathrm{C}$ valores superiores de PI em comparação aos amidos de baixa e intermediária amilose (Figura 5 e 6). Este comportamento também foi encontrado em outros estudos de Zavareze et al. (2010) ${ }^{26}$; Freitas e Leonel (2008) ${ }^{27}$; Yonemoto, Calori-Domingues e Franco $(2007)^{28}$ sobre propriedades do amido, nos quais amidos isentos de amilose mostraram-se com inchamento superior, mesmo após um período prolongado de aquecimento. Demonstra-se, assim, que um dos fatores que interferem no intumescimento do amido é o conteúdo de amilose, pois a alta quantidade de amilose reduz o poder de inchamento.

A redução do PI dos grânulos de amido tem sido atribuída aos seguintes fatores: aumento da cristalinidade e redução da hidratação, interação entre as moléculas de amilose e/ou entre amilopectina, aumento da força de ligação intramolecular e da resistência do grânulo

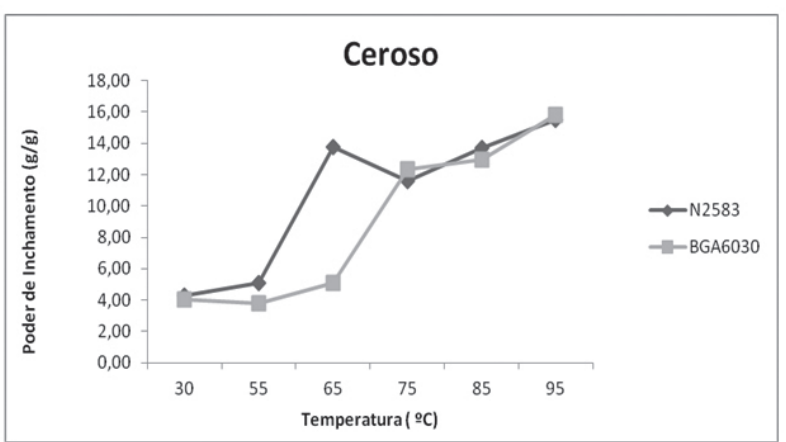

Figura 4. Curva do poder de inchamento (PI\%) dos diferentes amidos cerosos.

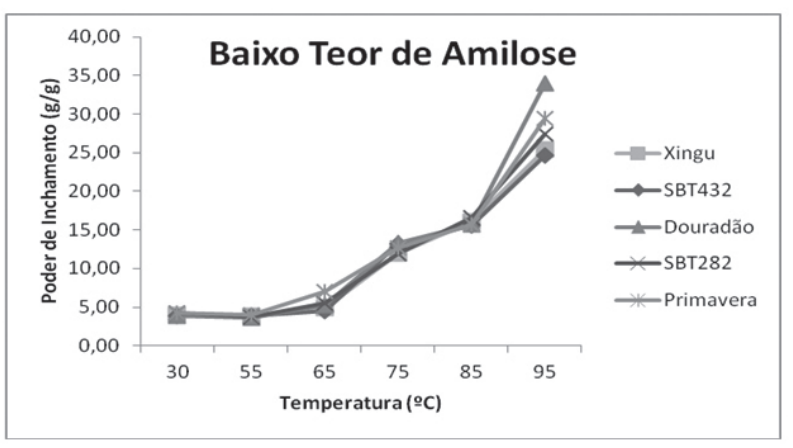

Figura 5. Curva do poder de inchamento (PI\%) dos diferentes amidos com baixo teor de amilose.

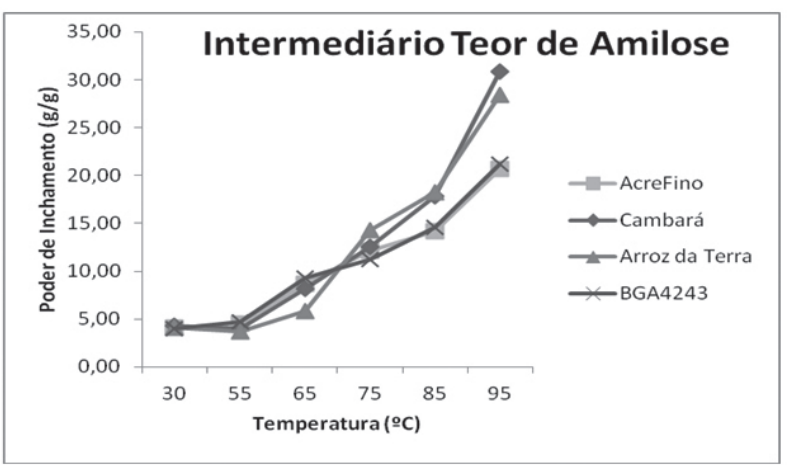

Figura 6. Curva do poder de inchamento (PI\%) dos diferentes amidos com teor de amilose intermediário.

e a formação do complexo amilose-lipídio, e essa compreensão da estrutura dos grânulos de amido é importante no entendimento de suas propriedades físicoquímicas, as quais determinam o comportamento do amido nos mais diversos processos industriais a que eles normalmente são submetidos ${ }^{18,30,31}$. 


\section{Conclusão}

Com base nos resultados, foram observados três distintos grupos de amilose dos onze genótipos (ceroso, baixo e intermediário) analisados. Em relação ao tamanho dos grânulos de arroz, foram caracterizados na forma poliédrica, de irregulares e com faces distintas e angulares para todos os genótipos. Notou-se que amidos de arroz ricos em amilose mostraram poder de inchamento e solubilidade inferiores, mesmo submetidos a maiores temperaturas.

Portando, é possível concluir que há relação entre diferentes propriedades relacionadas a tamanho dos grânulos e poder de inchamento, juntamente com o teor de amilose em amidos de arroz, são ferramentas significativas para predizer o comportamento de diferentes genótipos de arroz, auxiliando a diferenciar características peculiares.

\section{Agradecimentos}

Coordenação de Aperfeiçoamento de Pessoal de Nível Superior (CAPES) e à Embrapa Arroz e Feijão, pelo apoio financeiro.

\section{Referencias}

1. Castro, E. M.; Vieira, N. R. A.; Rabelo, R. R.; Silva, S. A. Qualidade de grãos em arroz. Santo Antônio de Goiás: Embrapa Arroz e Feijão, 30 p. 1999.

2. Singh, N. et al. Morphological, thermal and rheological properties of starches from different botanical sources. Food Chemistry, v.81, n.219-231, 2003.

3. Vieira, N. R. A.; Rabelo, R. R. Qualidade tecnológica. I: SANTOS, A. B.; STONE, L.F.; VIEIRA, N. R. A. (Ed.). A cultura do arroz no Brasil. 2. ed. Santo Antônio de Goiás,Embrapa Arroz e Feijão,. cap. 23, p. 969-1005, 2006.

4. Dias, A. R. G.; Zavareze, E. R,; Spier, F.; Castro, L. A. S.; Gutkoski, L. C. Effects of annealing on the physicochemical properties and enzymatic susceptibility of rice starches with different amylose contents. Food Chemistry, Oxford, v. 123, p. 711-719, 2010.

5. Webber, F. H.; Collares-Queiroz, F. P.; Chang, Y. K. Caracterização físico-química, reológica, morfológica e térmica dos amidos de milho normal, ceroso e com alto teor de amilose. Ciência e Tecnologia de Alimentos, Campinas, v. 29, n. 4, p. 748-753, 2009.

6. Wani, A. A.; Singh, P.; Shah, M. A.; Schweiggert-Weisz, U.; Khalid; Wani, G. I. A. Rice starch diversity: effects on structural, morphological, thermal, and physicochemical properties - A review. Comprehensive Reviews in Food Science and Food Safety, Malden,

\section{v. 11, n. 5 , p. $417-436,2012$}

7. Fitzgerald, M. A.; Mccouch, S. R.; Hall, R. D. Not just a grain of rice: the quest for quality. Trends in Plant Science, Oxford, v. 14, n. 3, p. 133-139, 2009.

8. Wang, L.; Wang, Y. J. Rice starch isolation by neutral protease and high-intensity ultrasound. Journal of Cereal Science, London, v. 39, n. 2, p. 291-296, 2004.

9. Schoch, T. J. Swelling power and solubility of granular starches. In: WHISTLER, R. L. (ed). Methods in Carbohydrate Chemistry, New York: Academic Press, p. 106-109. v. 4. 1964.

10. Walter, M.; Marchezan, E.; Avila, L. A. Arroz: composição e características nutricionais. Ciência Rural, Santa Maria, v. 38, n. 4, p. 1184-1192, 2008.

11. Techawipharat, J.; Suphantharika, M.; Bemiller, J.N. Effects of cellulose derivatives and carrageenans on the pasting, paste, and gel properties of rice starches. Carbohydrate Polymers, v. 73, n. 3, p. 417426, 2008.

12. Pereira, J. A.; Rangel, P. H. N. Produtividade e qualidade de grãos de arroz irrigado no Piauí. Ciência Agrotecnologia, v. 25, n. 3, p. 569$575,2001$.

13. Frei, M. et al. Studies on in vitro starch digestibility and the glycemic index of six different indigenous rice cultivars from the Philippines. Food Chemistry, v.83, p.395-402, 2003.

14. Juliano, B.O. Polysaccharides, proteins, and lipids of rice. In: JULIANO, B.O. (Ed.). Rice: chemistry and technology. Minnesota, USA: American Association of Cereal Chemists, Cap.3, p.17-57, 1985.

15. Franco, C. M. L.; Cabral, R. A. F.; Tavares, D. Q. Structural and physicochemical of lintnerized native and sour cassava starches. Starch/ Starke, Weinheim, v. 54, p. 469-475, Apr. 2002.

16. Qi-Hua, L.; Xue-Biao, Z.; Lian-Qun, Y.; Tian, L. Effects of chalkiness on cooking, eating and nutritional qualities of rice in two indica varieties. Rice Science, Hangzhou, v. 16, n. 2, p. 161-164, 2009.

17. Kong, X. ; Zhu, P.; Sui, Z.; Bao, J. Physicochemical properties of starches from diverse rice cultivars varying in apparent amylose content and gelatinisation temperature combinations. Food Chemistry, Oxford, v. 172, p. 433-440, 2015.

18. Mir, S. A.; Bosco, S. J. D. Cultivar difference in physicochemical properties of starches and flours from temperate rice of Indian Himalayas. Food Chemistry, Oxford, v. 157, p. 448-456, 2014.

19. Wani, A. A.; Singh, P.; Shah, M. A.; Schweiggert-Weisz, U.; Khalid; Wani,G. I. A. Rice starch diversity: effects on structural, morphological, thermal, and physicochemical properties - A review. Comprehensive Reviews in Food Science and Food Safety, Malden, v. 11, n. 5, p. 417-436, 2012.

20. Lawal, O. S. et al. Rheology and functional properties of starches isolated from five improved rice varieties from West Africa. Food Hydrocolloids, Amsterdam, v. 25, n. 7, p. 1785-1792, 2011.

21. Riley, C. K.; Wheatley, A. O.; Asemota, H. N. Full length research 
paper isolation and characterization of starches from eight Dioscorea alata cultivars grown in Jamaica. African Journal of Biotechology, v. 5, n. 17, p. 1528-1536, 2006.

22. Kaur, A.; Singh, N.; Ezekiel, R.; Sodhi, N. S. Properties of starches separated from potatoes stored under different conditions. Food Chemistry, Oxford, v. 114, p. 1396-1404, 2009.

23. Kaur, A.; Singh, N.; Sodhi, N. S. Some properties of potatoes and their starches II. Morphological thermal and rheological properties of starches. Food Chemistry, Oxford, v. 79, n. 2, p. 183-192, 2002.

24. Gani, A.; Wani, S. M.; Masoodi, F. A.; Salim, R. Characterization of rice starches extracted from Indian cultivars. Food Science and Technology International, London, v. 19, n. 143-152, 2013.

25. Simi, C. K.; Abraham, T. E. Physicochemical, rheological and thermal properties of Njavara rice (Oryza sativa) starch. Journal of Agricultural and Food Chemistry, Washington, v. 56, p. 1210512113, 2008.

26. Zavareze, E. Da R.; Pereira, J. M.; Moura, F. A.; Spier, F.; Helbig, E. Teor de amido resistente e perfil de textura de amidos de arroz com diferentes níveis de amilose modificados hidrotermicamente. Brazilian Journal Tecnology, campinas, v. 13, p. 96-101, 2010.

27. Freitas, T. S.; Leonel, M. Amido resistente em fécula de mandioca extrusada sob diferentes condições operacionais. Alimentos e Nutrição, Araraquara, v.19, n.2, p. 183-190, 2008.

28. Yonemoto, P. G.; Calori-Domingues, M. A.; Franco, C. M. L. Efeito do tamanho dos grânulos nas características estruturais e físicoquímicas do amido de trigo. Ciência e Tecnologia de Alimentos, Campinas, v. 27, p. 761-771, 2007.

29. Sodhi, N. S.; Singh, N. Morphological, thermal and rheological properties of starches separated from rice cultivars grown in India. Food Chemistry, Oxford, v. 80, p. 99-108, 2003.

30. Jane, J.; Chen, Y. Y.; Lee, L. F.; Mcpherson, A. E.; Wong, K. S.; Radosavljevic, M. Effects of amylopectin branch chain length and amylose content on the gelatinization and pasting properties of starch. Cereal Chemistry, St Paul, v. 76, p. 629-637, 1999.

\section{Raíza C. Fonseca' \& Priscila Z. Bassinello}

\footnotetext{
${ }^{1}$ Instituto SENAI de Tecnologia em Alimentos e Bebidas,- Rua Professor Lázaro Costa nº 348, Vila Canaã, CEP: 74415-420, Goiânia, Goiás, Brasil.

${ }^{2}$ Embrapa Arroz e Feijão, Rodovia GO-462 km 12, CEP: 75375-000 Zona Rural, Santo Antônio de Goiás - Goiás, Brasil.
}

*E-mail: raiza.cavalcante@gmail.com 